\title{
The effect of addition of modified guar gum to a low- energy semisolid meal on appetite and body weight loss.
}

Citation for published version (APA):

Kovacs, E. M. R., Westerterp-Plantenga, M. S., Saris, W. H. M., Goossens, I., Geurten, P., \& Brouns, F. J. P. H. (2001). The effect of addition of modified guar gum to a low-energy semisolid meal on appetite and body weight loss. International Journal of Obesity, 25, 307-315. https://doi.org/10.1038/sj.ijo.0801546

Document status and date:

Published: 01/01/2001

DOI:

10.1038/sj.ijo.0801546

Document Version:

Publisher's PDF, also known as Version of record

\section{Please check the document version of this publication:}

- A submitted manuscript is the version of the article upon submission and before peer-review. There can be important differences between the submitted version and the official published version of record. People interested in the research are advised to contact the author for the final version of the publication, or visit the DOI to the publisher's website.

- The final author version and the galley proof are versions of the publication after peer review.

- The final published version features the final layout of the paper including the volume, issue and page numbers.

Link to publication

\footnotetext{
General rights rights.

- You may freely distribute the URL identifying the publication in the public portal. please follow below link for the End User Agreement:

www.umlib.nl/taverne-license

Take down policy

If you believe that this document breaches copyright please contact us at:

repository@maastrichtuniversity.nl

providing details and we will investigate your claim.
}

Copyright and moral rights for the publications made accessible in the public portal are retained by the authors and/or other copyright owners and it is a condition of accessing publications that users recognise and abide by the legal requirements associated with these

- Users may download and print one copy of any publication from the public portal for the purpose of private study or research.

- You may not further distribute the material or use it for any profit-making activity or commercial gain

If the publication is distributed under the terms of Article $25 \mathrm{fa}$ of the Dutch Copyright Act, indicated by the "Taverne" license above, 


\title{
The effect of addition of modified guar gum to a low-energy semisolid meal on appetite and body weight loss
}

\author{
EMR Kovacs $^{1 *}$, MS Westerterp-Plantenga ${ }^{1}$, WHM Saris ${ }^{1}$, I Goossens ${ }^{1}$, P Geurten $^{1}$ and F Brouns ${ }^{1}$
}

\author{
${ }^{1}$ Department of Human Biology, Maastricht University, Maastricht, The Netherlands
}

OBJECTIVE: To investigate the effect of addition of modified guar gum (GG) to a low-energy semisolid meal on appetite and body weight (BW) loss.

SUBJECTS: Twenty eight mainly overweight male volunteers (age, 19-56y; body mass index, $29 \pm 2 \mathrm{~kg} \mathrm{~m}^{-2}$; BW, $89.4 \pm 9.2 \mathrm{~kg}$ ).

DESIGN: Baseline of one week with self-selected diet. Three treatments of 2 weeks with a low-energy diet divided over three times a day, consisting of a semisolid meal with (SSM+) or without GC (SSM) or a solid meal (SM) with the same energy content ( $947 \mathrm{kl})$ and macronutrient composition, and a dinner of the subject's own choice. Washout periods lasted 4 weeks. RESULTS: Compared to baseline values, reduction in energy intake and BW loss were similar for SSM +, SSM and SM. Appetite (hunger, desire to eat or estimation of how much one could eat) was increased in SSM and in SM compared to baseline, but not in SSM +. Satiety and fullness in SSM +, SSM and SM were similar to baseline. Any intervention was more effective on BW loss when it took place the first time compared to the second and third times $(2.6 \pm 0.2 \mathrm{~kg}, 1.7 \pm 0.2 \mathrm{~kg}$ and $1.1 \pm 0.2 \mathrm{~kg}$, respectively; $P<0.001)$. The SM-SSM + -SSM sequence was more effective on BW loss compared to the SSM $+-5 S M-S M$ sequence $(5.6 \pm 1.0$ and $2.5 \pm 0.6 \mathrm{~kg}$, respectively; $P<0.05)$.

CONCLUSION: All the three treatments were equally effective with respect to BW loss. GG addition to a semisolid meal prevented an increase in appetite, hunger and desire to eat, which increase was present in the other treatments. However, differences between treatments were not statistically significant. The order effect shows that repeated 2-week bouts of dieting become increasingly ineffective. The sequence SM-SSM + -SSM was more effective than the sequence SSM + -SSM-SM, probably because compliance was relatively higher with the SSM + or SSM diet, and compliance decreased towards the end of the complete experiment.

International Journal of Obesity (2001) 25, 307-315

Keywords: guar gum; energy intake; body weight loss; appetite; obesity treatment

\section{Introduction}

The increasing incidence of obesity is a recognized medical problem in developed countries. ${ }^{3}$ Obesity is known to be related to increased risks of coronary heart diseases, hypertension, non-insulin-dependent diabetes mellitus and certain types of cancer. ${ }^{2-4}$ Factors suggested to be related to the development of obesity are decreased physical activity and

"Correspondence: EMR Kovacs, Department of Human Biology, Maastricht University, PO Box 616, 6200 MD Maastricht, The Netherlands.

E-mail: E.Kovacs@HB.UNIMAAS.NL

Received 17 December 1999; revised 4 September 2000; accepted 2 October 2000 increased energy intake, especially fat intake. Weight loss and loss of body fat can thus be achieved by reducing energy intake and/or increasing energy expenditure. Low-energy diets have been shown to be successful in the reduction of body weight on the short term. However, during long-term treatment, decreased compliance and increased habituation to an energy-restricted diet accompanied by increased appetite ${ }^{5}$ may result in unsuccessful weight loss or prevention of weight regain. Reduced hunger and increased satiety feelings may improve compliance to an energy-restricted diet. $^{6}$ Therefore, identification of substances that improve or sustain satiety during energy restriction is needed for the treatment of obesity. The effects of dietary fiber on appetite, energy intake and/or body weight have been extensively investigated and reported in a number of reviews. ${ }^{7-9}$ Dietary 
fiber such as guar gum (GG) was found to effectively increase fullness and satiety, resulting in reduced energy intake. ${ }^{10,11}$ It has been proposed that soluble viscous fiber, such as (GG), may decrease the rate of gastric emptying and small intestinal transit, ${ }^{12-14}$ resulting in a delayed glucose absorption $^{15}$ and a prolonged feeling of satiety. ${ }^{16}$ The lowered energy intake and increased satiety feeling may be beneficial for short-term weight $\operatorname{loss}^{10}$ and long-term weight maintenance. ${ }^{17,18}$

Controversial findings have been shown on the effects of different types of dietary fiber along with an energy-restricted diet on food intake and/or body weight loss. ${ }^{6,19-23}$ To our knowledge, only one study investigated the effects of GG supplementation during energy restriction on energy intake, hunger and satiety. "The hunger-reducing effect of GG during the energy restricted condition suggested that GG may be useful in the treatment of obesity, by increasing the compliance to a low-energy diet. Moreover, we assessed a new type of GG, namely a highly purified dietary galactomannan fiber that forms a gel in 5-7 min after adding water. Furthermore we combined the energy-providing meal directly with the GG.

The aim of the present study was to test the hypothesis that the addition of modified GG to a ready-to-eat low energy semisolid meal was effective in sustaining satiety while reducing food intake. It was hypothesized that GG addition to a low-energy semisolid meal would lead to gel forming in the stomach, resulting in sustained feeling of satiety or prevention of increase of appetite or hunger. Moreover, this was expected to result in a more effective body weight (BW) loss. Furthermore, since the possible effect of a treatment with the ready-to-eat low-energy semisolid meal has not been tested yet, another aim of the study was to compare the effects of the semisolid meal itself with a selfprepared low-energy solid diet on appetite and BW loss.

\section{Methods \\ Subjects}

The study was started with 36 male mainly overweight subjects who were recruited by advertisements in local newspapers. Eight subjects dropped out of the study: six subjects stopped participation before (baseline) or during the first intervention because they were not able to follow our prescriptions, mostly because of a lack of time, and two subjects stopped during the third intervention because they moved far away. Statistical analysis revealed no difference in the number of dropouts between treatment sequences. Therefore the data presented in this study are based upon 28 subjects. Baseline subject characteristics are presented in Table 1 . The nature and risks of the experimental procedure were explained to the subjects, and all subjects gave their written informed consent. The study protocol was approved by the Ethical Committee of the Maastricht University.
Table 1 Subjects characteristics $(n=28)$ at baseline

\begin{tabular}{|c|c|c|}
\hline & Meants.d. & Range \\
\hline Age $(y)$ & $42.5 \pm 10.5$ & $19-56$ \\
\hline Height (m) & $1.77 \pm 0.05$ & $1.65-1.89$ \\
\hline Weight (kg) & $89.4 \pm 9.2$ & $74.1-112.7$ \\
\hline Body mass index $\left(\mathrm{kg} \mathrm{m}^{-2}\right)$ & $28.6 \pm 2.1$ & $24.1-33.7$ \\
\hline Waist circumference $(\mathrm{cm})$ & $98 \pm 7$ & $85-108$ \\
\hline Hip circumference $(\mathrm{cm})$ & $104 \pm 6$ & $89-119$ \\
\hline Waist-hip ratio & $0.95 \pm 0.05$ & $0.85-1.06$ \\
\hline Body fat $(\%)(n=15)$ & $30.9 \pm 1.1$ & $23.3-38.5$ \\
\hline Systolic blood pressure $(\mathrm{mmHg})$ & $151 \pm 22$ & $116-206$ \\
\hline Diastolic blood pressure $(\mathrm{mmHg})$ & $92 \pm 10$ & $77-115$ \\
\hline Blood glucose $\left(\mathrm{mmol} \mathrm{I}^{-1}\right)$ & $5.4 \pm 0.3$ & $4.4-6.0$ \\
\hline F1 (cognitive restraint) & $5 \pm 3$ & $0 \pm 9$ \\
\hline F2 (distnhibition) & $4 \pm 2$ & $1 \pm 12$ \\
\hline F3 (hunger) & $4 \pm 3$ & $0 \pm 11$ \\
\hline Herman-Polivy restraint & $14 \pm 5$ & $6 \pm 22$ \\
\hline
\end{tabular}

\section{Experimental design}

The experimental design consisted of a baseline period of 1 week and then three intervention periods of 2 weeks in a randomized cross-over design. The intervention periods were separated by washout periods of 4 weeks (Figure 1).

During baseline and the washout periods, the subjects consumed a self-selected diet. During the intervention periods, the subjects consumed for breakfast, lunch and as a four o'clock snack a low-energy meal. In addition, for lunch, subjects were allowed to eat a piece of fruit (eg apple, pear or orange). For dinner, the subjects ingested what they liked, but they were instructed to drink not more than one glass of alcoholic beverage or soft drink. Subjects were instructed to refrain from snacks between meals. During the day, the subjects were allowed to drink ad libitum water, coffee and tea (without sugar and milk).

The low-energy meal consisted of a semisolid meal (Milical Crème, Laboratoires Diététique et Santé, Revel, France) with (SSM +) or without (SSM) supplementation of $2.5 \mathrm{~g}$ of a new type of modified GG (Meyprofin ${ }^{\mathrm{B}} \mathrm{M}-175$, Meyhall AG, Kreuzlingen, Switzerland), a highly purified dietary galactomannan fiber which forms a gel in about 5-7 min after adding water, or a solid meal (SM) with the same energy content and macronutrient composition (energy, $947 \mathrm{~kJ}$; protein, $17.9 \mathrm{~g}$; carbohydrate, $21.0 \mathrm{~g}$; fat, $7.9 \mathrm{~g}$ ), which was prepared by the subjects themselves using our instructions. Acceptability of these meals was tested in the subjects as well. Subjects, matched for BMI, age, weight and blood glucose, were included in three intervention sequences, that is SSM+-SSM-SM $(n=10)$, SSM-SM-SSM+ $(n=9)$, and SM-SSM $+-\operatorname{SSM}(n=9)$.

\section{Anthropometry}

Body weight was measured during screening, at the beginning and at the end of baseline as well as at the beginning, after 1 week and at the end of each intervention period on a 


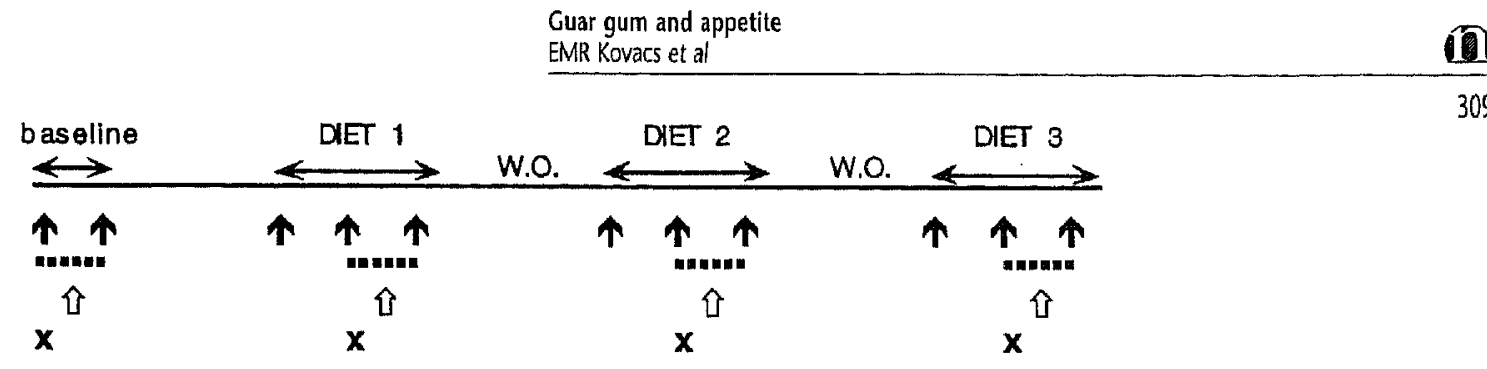

DIET 1, DIET 2, DIET 3 = intervention periods; W.O. = washout periods; $\uparrow=$ measurement of body weight; $\cdots \cdot \ldots+$ = recording of food intake; 0 = questionnaires on hunger and satiety and eating behavior; $\mathbf{X}=$ measurement of body fat

Figure 1 Experimental design.

digital balance (Seca, model 707, Hamburg, Germany; weighing accuracy of $0.1 \mathrm{~kg}$ ) with subjects in underwear, in a fasted state and after voiding their bladder. Height was measured using a wail-mounted stadiometer (Seca, model 220, Hamburg, Germany). The body mass index was calculated as BW height ${ }^{-2}\left(\mathrm{~kg} \mathrm{~m}^{-2}\right)$.

The distribution of fat was investigated during screening and at the end of the experiment by measuring the waist and hip circumferences and calculating the waist-hip ratio (WHR). The waist circumference was measured at the site of the smallest circumference between the rib cage and the ileac crest, with the subjects in standing position. The hip circumference was measured at the site of the largest circumference between the waist and the thighs. The WHR was calculated by dividing the waist circumference by the hip circumference. Total body water (TBW) was measured before baseline and during each intervention period in a random subsample of 15 subjects using the deuterium $\left({ }^{2} \mathrm{H}_{2} \mathrm{O}\right)$ dilution technique. ${ }^{24}$ The dilution of the deuterium isotope is a measure for total body water (TBW). ${ }^{25}$ Subjects were asked to collect a urine sample in the evening just before drinking a weighed amount of deuterium-enriched water solution. After ingestion of the deuterium solution no further fluid or food consumption was permitted. Ten hours after ingestion of the deuterium solution a second urine samples (second voiding) was collected. Deuterium concentration in the urine samples was measured using an isotope ratio mass spectrometer (Micromass Optima, Manchester, UK). TBW was obtained by dividing the measured deuterium dilution space by $1.04 .{ }^{24}$ Fat-free mass (FFM) was calculated by dividing the TBW by the hydration factor 0.73. By subtracting FFM from BW, fat mass (FM) was obtained. FM expressed as a percentage of $\mathrm{BW}$ revealed body fat percentage.

\section{Blood parameters}

Systolic and diastolic blood pressure were measured during screening by an automatic blood pressure monitor (Omron $705 \mathrm{CP}$, Omron Healthcare GmbH, Hamburg, Germany). A fasted blood sample $(2 \mathrm{ml})$ was obtained and mixed with EDTA to prevent clotting. Plasma was obtained by centrifugation and then stored at $-20^{\circ} \mathrm{C}$ until analysis of glucose by a hexokinase method (Cobas Bio, Roche Diagnostics, Hoffmann-La Roche, Basel, Switzerland).

\section{Eating behavior}

Eating behavior was analyzed during screening as well as at the beginning and at the end of baseline and of each intervention period using a validated Dutch translation of the Three Factor Eating Questionnaire (TFEQ). ${ }^{26,27}$ Cognitive restrained and unrestrained eating behavior (factor 1 ), emotional eating and disinhibition (factor 2) and the subjective feeling of hunger (factor 3 ) were scored. Body weight fluctuation was investigated with the Herman Polivy questionnaire $(\mathrm{HP})^{28}$

\section{Food intake}

Food intake and meal frequency were recorded during the last 7 days of each intervention period using a food intake diary. Personal instruction was given in advance. The food intake diaries were analyzed using the Dutch food composition table ${ }^{29}$ and the accessory computer program (Becel Nutrition Program 1988).

Compliance of the subjects to the dietary instructions was checked using the food intake diaries. For each incorrect food intake action (eg consumption of only two lowenergy meals during a day, extra alcoholic beverage during 

Compliance to dietary instructions was analyzed using these points.

Accuracy of food intake recording was determined in a random subsample of 15 subjects by comparing water intake and water loss. ${ }^{30}$ Water intake was measured using a food intake diary. Water intake was determined from reported food intake using a computer program (Becel Nutrition Program 1988) based on food tables. ${ }^{29}$ Water loss was measured with the deuterium elimination method. ${ }^{31}$ The evening before the start of the recording week, the subjects drank a weighed amount of deuterium solution $\left({ }^{2} \mathrm{H}_{2} \mathrm{O}\right)$ after collecting a baseline urine sample. Water loss was calculated from ${ }^{2} \mathrm{H}$ elimination in urine samples, collected on day $\mathbf{1}$ (in the morning and in the evening), day 7 (in the evening) and day 8 (in the morning). ${ }^{31,32}$ Deuterium content in the urine samples was measured with an isotope ratio mass spectrometer (Micromass Optima, Manchester, UK). Under normal conditions, water balance is preserved and water intake matches water loss. When water intake, corrected for metabolic water, is less than water loss, underrecording is present. ${ }^{30}$ The deuterium dilution method was validated with the doubly labelled water method, showing that the recording precision of water intake was representative for total food recording. ${ }^{30,33}$ To ensure that food recording in these 15 subjects was not influenced by the fact that they were aware that water intake and water loss were measured, the other subjects also followed the same protocol, but using tap water.

\section{Satiety}

Perception of satiety (hunger, satiety, fullness, desire to eat, appetite, estimation of how much one could eat, and thirst) was scored on anchored $100 \mathrm{~mm}$ visual analog scales at day 4 during baseline and day 11 during each intervention period. Questionnaires were completed at 10 fixed time points, respectively just before and after breakfast, in the morning between $1000 \mathrm{~h}$ and $1100 \mathrm{~h}$, before and after lunch, before and after a four $o^{\prime}$ clock snack, before and after dinner and in the evening between 2200 and $2300 \mathbf{h}^{27}$

To characterize the development of satiation during a meal, questions on hunger, satiety and pleasantness of taste were answered on $100 \mathrm{~mm}$ visual analogue scales every 2 min during dinner consumed on the same day.

\section{Tolerance}

Tolerance of the intervention diets was determined at the end of each diet period using a questionnaire on occurrence of gastrointestinal and other complaints and scored on a five point scale $(0=$ never, $1=$ rarely, $2=$ sometimes, $3=$ often, $4=$ very often).

Hedonic value and user-friendliness

Hedonic value and user-friendliness of the treatments were determined using a questionnaire which the subjects were asked to complete at the end of the experiment. The hedonic value of the semisolid meal was scored on a $0-5$ scale $(0=$ not tasty at all, $1=$ not tasty, $2=$ less tasty, $3=$ rather tasty, $4=$ tasty, $5=$ very tasty). User-friendliness of the diets was scored on a $0-2$ scale $(0=$ not user-friendly at all, $1=$ rather user-friendly, $2=$ user-friendly) and subjects were asked to say which diet they would prefer to use in the future.

\section{Statistical analysis}

Data are presented as mean \pm standard error (s.e.). Differences between baseline and the treatments as well as differences between the treatments were determined by analysis of variance for repeated measures (ANOVA) and Sheffe-F post-hoc test (Statview SE Graphics ${ }^{\mathrm{TM}}$ ). The measurements at baseline and at the end of the experiment were compared using paired $t$-tests. Pearson correlation coefficients were calculated to determine the relationship between selected variables. Level of significance was set at $P<0.05$.

\section{Results}

During the entire experiment BW decreased by $4.4 \pm 0.7 \mathrm{~kg}$ and BMI by $1.4 \mathrm{~kg} \mathrm{~m}^{-2}(P<0.001)$ in the whole group. Waist and hip circumferences were reduced both by $4 \mathrm{~cm}$ $(P<0.001)$. The WHR did not change during the experiment. Body fat percentage determined in 15 subjects decreased by $3.8 \%(P<0.01)$.

Blood pressure also decreased during the experiment (diastolic, $-17 \mathrm{mmHg}$; systolic, $-10 \mathrm{mmHg} P<0.001$ ). No change was found in blood glucose concentration.

Scores on the Herman Polivy questionnaire (frequency of dieting) and scores for factor 2 (disinhibition) and 3 (hunger) of the TFEQ were similar for all treatments. For factor 1 (restrained eating) significantly increased scores were found during each of the intervention periods compared to baseline $(P<0.01)$.

BW loss during 2 weeks treatment, irrespective of the order of treatment, was $2.1 \pm 0.3,1.6 \pm 0.2$ and $1.7 \pm 0.3 \mathrm{~kg}$ during SSM +, SSM and SM, respectively, with no significant differences between treatments. During the first intervention period BW loss was greater than during the second and third intervention periods $(2.6 \pm 0.2, \quad 1.7 \pm 0.2$ and $1.1 \pm 0.2 \mathrm{~kg}$, respectively; $P<0.001)$. SSM + and SSM treatments resulted in an acute effect on BW. In SSM + and SSM, BW loss was greater during the first compared to the third intervention period (SSM,$+ P<0.01$; SSM, $P<0.05$ ). Treatment SM showed no difference in BW loss with respect to the different sequences. The SM-SSM+-SSM intervention sequence was more effective in reducing BW than SSM +- SSM-SM $(P<0.05)$. From the start to the end of 
intervention, the subjects lost $5.6 \pm 1.0 \mathrm{~kg}$ in the $S M-$ SSM + -SSM sequence, $4.6 \pm 1.0 \mathrm{~kg}$ in the SSM-SM$\mathrm{SSM}+$ sequence and $2.5 \pm 0.6 \mathrm{~kg}$ in the $\mathrm{SSM}+-\mathrm{SSM}-\mathrm{SM}$ sequence.

Reported energy intake was significantly lower during the intervention periods compared to baseline (baseline, $\quad 10.2 \pm 0.4 \mathrm{MJ} \mathrm{day}^{-1} ; \quad \mathrm{SSM}_{+}, \quad 6.7 \pm 0.3 \mathrm{MJ} \mathrm{day}^{-1}$, $F_{(1,27)}=31.5, \quad P<0.001 ; \quad$ SSM, $\quad 6.9 \pm 0.2 \mathrm{MJ} \mathrm{day}^{-1}$, $F_{(1,27)}=29.1, P<0.001 ; \mathrm{SM}, 6.9 \pm 0.2 \mathrm{MJ} \mathrm{day}^{-1}, F_{(1,27)}=29.4$, $P<0.001)$ and not different between treatments. The level of underrecording determined in 15 subjects was similar for all trials (baseline, $21 \%$, range $-7-58 \%$; SSM,$+ 22 \%$, range $-27-60 \%$; SSM, $18 \%$, range $-35-55 \%$; SM, $24 \%$, range $-26-75 \%)$. The reported energy intake was corrected for the level of underreporting (baseline, $12.3 \mathrm{MJ}^{\text {day }}{ }^{-1}$; SSM+, 8.2 $\mathrm{MJ} \mathrm{day}^{-1}$; SSM, 8.1 MJ day ${ }^{-1} ; \mathrm{SM}, 8.6 \mathrm{MJ}^{\text {day }}{ }^{-1}$ ). Energy deficit was therefore $4.2,4.2$ and $3.8 \mathrm{MJ}^{\text {day }}{ }^{-1}$ for $\mathrm{SSM}+$, SSM and SM, respectively. With an energy cost of weight loss of $30 \mathrm{MJ} \mathrm{kg}^{-1}$, this would result in a total expected body weight loss of $5.9 \mathrm{~kg}$ during the three treatments combined. This is in line with the body weight loss found in this study $(5.4 \mathrm{~kg})$. Reduced energy intake resulted from reduction in fat, carbohydrate and alcohol intake (Figure 2).

The following results on food intake are derived from the records in the food intake diaries. Fat, carbohydrate and alcohol intake was similar between the intervention periods. Dietary fiber intake was reduced in the SSM treatment $(P<0.001)$. Energy intake from the low-energy meals was higher during SSM + and SSM compared to SM (2.5 \pm 0.1 , $2.5 \pm 0.1$ and $2.1 \pm 0.1 \mathrm{MJ}$, respectively; $p<0.001$ ). Energy intake from the free dinner was $3.4 \pm 0.2,3.3 \pm 0.2$ and $3.1 \pm 0.2 \mathrm{MJ}$ during SSM,+ SSM and SM, respectively (NS). Energy intake from the snacks was lower in the SSM+ treatment $(0.8 \pm 0.2 \mathrm{MJ})$ compared to SM $(1.6 \pm 0.3 \mathrm{MJ}$; $P<0.01$ ) and was $1.0 \pm 0.2 \mathrm{MJ}$ during SSM. Food intake during each intervention was decreased during breakfast, in the morning, during lunch, and in the evening compared to baseline $(P<0.001)$, but was similar during dinner $(P=0.61$, Figure 3$)$,

Energy intake during the dinner was similar for all situations (baseline, $3.1 \pm 0.2 \mathrm{MJ} ; \mathrm{SSM}+, 3.4 \pm 0.3 \mathrm{MJ}$; SSM, $4.0 \pm 0.5 \mathrm{MJ} ; \mathrm{SM}, 3.1 \pm 0.3 \mathrm{MJ}$ ). The rate of change in satiety over the meal was smaller during SM compared to baseline $(P<0.05)$. The rate of change in hunger and pleasantness of taste was similar for all situations (Table 3 ).

As they were instructed, the subjects consumed more meals and fewer snacks during the intervention periods compared to baseline $(P<0.001)$. When considering the total number of meals plus snacks (eating moments), subjects ate more frequently during baseline compared to the

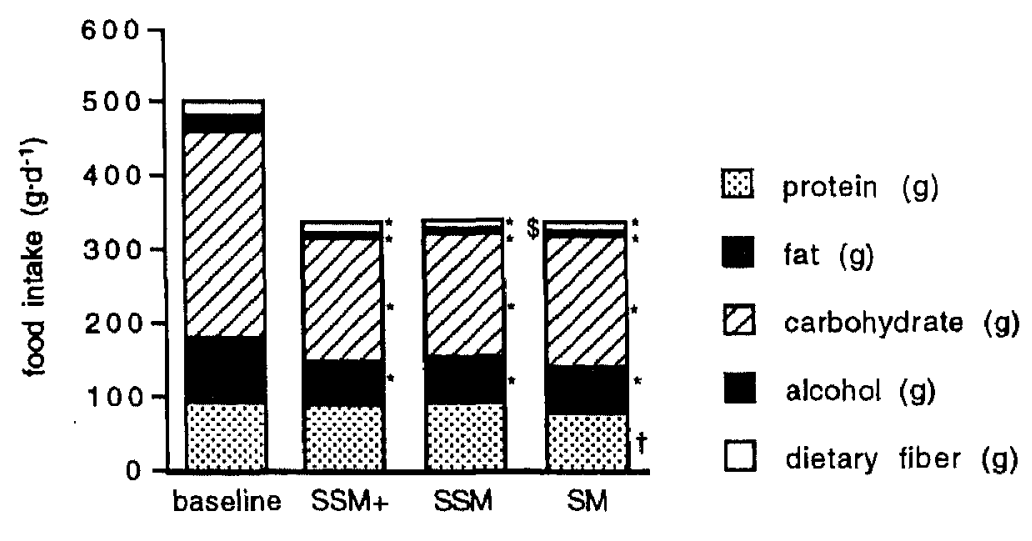

Values are mean.

$S S M+=$ semisolid meal with guar gum; $S S M=$ semisolid meal; $S M=$ solid

meal

Statistical significance was determined by an analysis of variance for repeated

measures (ANOVA). " SSM+, SSM and SM significantly different from

baseline ( $p<0.001) ;$ "SSM signiflcantly different from SSM+ and SM

$(p<0.001) i^{\dagger} S M$ significantly different from baseline and SSM $(p<0.01)$.

Figure 2 Daily food intake $\left(g \cdot d^{-1}\right)$ as recorded using a food intake diary. 


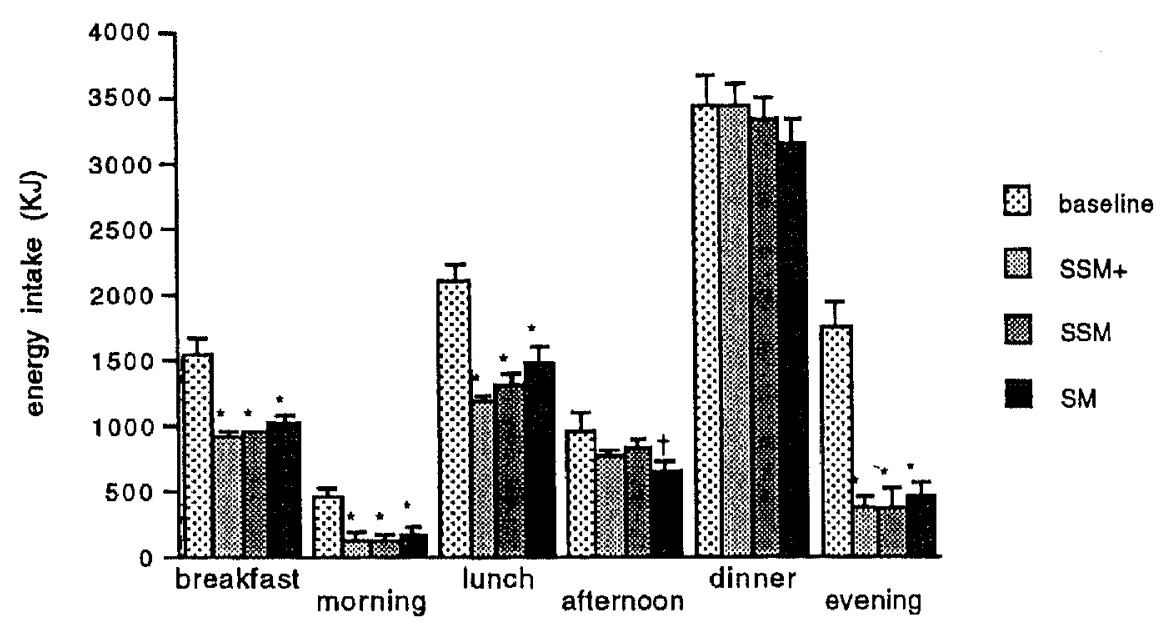

Values are mean \pm s.e.

$S S M+=$ semisolid meal with guar gum; $S S M=$ semisolid meal; $S M=$ solid

meal

Statistical significance was determined by an analysis of variance for repeated

measures (ANOVA). * SSM+, SSM and SM significantly different from

baseline $(p<0.001) ;{ }^{\dagger} S M$ significantly different from baseline $(p<0.01)$.

Figure 3 Food intake $(\mathrm{k})$ ) at different time points during the day.

Table 2 Area under the curve from the following $100 \mathrm{~mm}$ visual analog scale ratings over $16 \mathrm{~h}$, that is before and after breakfast, lunch, four o'clock snack and dinner, in the morning between 10 and $11 \mathrm{~h}$ and in the evening between 22 and $23 \mathrm{~h}(\mathrm{~mm} \mathrm{~h})$

\begin{tabular}{lccccc}
\hline & Baseline & SSM & SSM & SM & P \\
\hline Hunger & $470 \pm 30$ & $579 \pm 34$ & $663 \pm 43^{*}$ & $603 \pm 36^{*}$ & $<0.001$ \\
Appetite & $512 \pm 32$ & $588 \pm 35$ & $672 \pm 42^{*}$ & $615 \pm 37$ & $<0.01$ \\
Desire to eat & $517 \pm 31$ & $584 \pm 38$ & $707 \pm 41^{*}$ & $627 \pm 37$ & $<0.01$ \\
Fullness & $520 \pm 38$ & $595 \pm 36$ & $537 \pm 42$ & $553 \pm 38$ & NS \\
Satiety & $588 \pm 32$ & $606 \pm 34$ & $518 \pm 35$ & $591 \pm 30$ & NS \\
$\begin{array}{l}\text { Thirst } \\
\text { Estimation of } \\
\quad \text { how much one } \\
\text { could eat }\end{array}$ & $592 \pm 31$ & $576 \pm 41$ & $579 \pm 44$ & $564 \pm 40$ & NS \\
\hline
\end{tabular}

Values are meants.e. $S S M+=$ semisolid meal with guar gum; $S S M=$ semisolid meal; $S M=$ solid meal. Statistical significance was determined by an analysis of variance for repeated measures (ANOVA). *Significantly different from baseline; NS = no significance.

intervention $(P<0.001)$. In treatment $S M$, the subjects consumed fewer meals compared to SSM + and SSM $(P<0.001)$, but in total they had the same number of eating moments as in the treatments SSM + and SSM because they compensated with snacks. The number of reported meals, snacks and eating moments during baseline, but not during the intervention, was positively correlated with BMI at baseline $(r=0.39, r=0.47$ and $r=0.51$, respectively; $P<0.05$ ).

Compliance to the dietary instructions during treatment SM was less good compared to SSM + and SSM $(P<0.001)$, but compliance was not related to body weight changes (SSM,$+ r=0.32$; SSM, $r=0.33$; SM, $r=0.22 ; P>0.05$ ).

The ratings on the questions throughout the day, expressed as area under the curve (AUC), corrected for the subject's minimum score, are shown in Table 2. The AUC of hunger was higher during treatments SSM and SM compared to baseline, but not during treatment SSM + . Appetite, the estimation of how much one could eat and desire to eat (also expressed as AUC) during SSM treatment were higher compared to baseline; this was not the case during treatments SSM + and SM. However, the differences from baseline in AUC of the appetite-related parameters with the SSM+ treatment were not different from the differences from baseline following SSM or SM. The AUC of fullness, satiety and thirst was not different between the four situations.

Diets were well tolerated. Intervention SSM + resulted in a slightly higher incidence of nausea compared to SSM and SM (SSM,$+ 0.3 \pm 0.1 ;$ SSM, $0.0 \pm 0.0 ;$ SM, $0.0 \pm 0.0 ; P<0.05)$ and flatulence compared to SM $(\mathrm{SSM}+, 1.1 \pm 0.2 ; \mathrm{SSM}$, 
Table 3 Changes of the following $100 \mathrm{~mm}$ visual analog scale ratings over the self-selected dinner $\left(\mathrm{mm} \mathrm{min}^{-1}\right)$

\begin{tabular}{lrrrrr}
\hline & Baseline & SSM & \multicolumn{1}{c}{ SSM } & SM & P \\
\hline Change in satiety & $4.7 \pm 0.3$ & $3.9 \pm 0.4$ & $3.6 \pm 0.4$ & $3.6 \pm 0.4^{*}$ & $<0.05$ \\
Change in hunger & $-3.3 \pm 0.4$ & $-3.5 \pm 0.4$ & $-3.2 \pm 0.3$ & $-2.5 \pm 0.3$ & NS \\
Change in pleasantness of taste & $-1.7 \pm 0.5$ & $-1.2 \pm 0.5$ & $-1.3 \pm 0.3$ & $-1.1 \pm 0.5$ & NS \\
\hline
\end{tabular}

Values are mean \pm s.e.

$S S M+=$ semisolid meal with guar gum; $S S M=$ semisolid meal; $S M=$ solid meal. Statistical significance was determined by an analysis of variance for repeated measures (ANOVA); *Significantly different from baseline; NS = no significance.

$0.7 \pm 0.2 ; \mathrm{SM}, 0.3 \pm 0.1 ; P<0.05)$. However, values for complaints remained low.

The hedonic value of the semisolid meal was $3.8 \pm 0.1$ on a $0-5$ scale. User-friendliness of the semisolid meal was $1.9 \pm 0.1$ on a $0-2$ scale, while user-friendliness of the solid meal was $1.2 \pm 0.1(P<0.001)$. SSM + was rated as the most preferred treatment (by 18 out of 28 subjects) over SSM and SM (by 10 and six out of 28 subjects, respectively).

\section{Discussion}

All the three treatments were effective with respect to BW loss and EI reduction compared to baseline. Despite a reduced EI during the treatments compared to baseline, satiety, fullness and thirst had not changed. Nevertheless appetite-related parameters (hunger, appetite, desire to eat and estimation of how much one could eat) were increased with the semisolid meal alone and hunger with the solid meal. In contrast, addition of GG to the semisolid meal prevented an increase in appetite, hunger and desire to eat, although the differences between treatments were not statistically significant. Also, with the SSM + treatment snacking was significantly lower than with the SM treatment, indicating a better sustained satiety between meals. Therefore addition of $G G$ to the semisolid meal showed a rather modest effect on sustaining satiety or prevention of increased of hunger.

Modest weight loss of 5-10\%, which has been shown to contribute to reduction of mortality and morbidity in obese people, has been considered a realistic goal in dietary treatments. ${ }^{34,35}$ With supplementation of $\mathrm{GG}^{10,11}$ or other dietary fiber ${ }^{36}$ some positive results have been found in short-term studies. It has been proposed that soluble viscous fiber, such as GG, may influence satiety by decreasing the rate of gastric emptying and the small intestinal transit time. ${ }^{12-14}$ However, some recent studies also found opposite results. ${ }^{37-40}$ A decreased rate of gastric emptying and/or intestinal transit may delay glucose absorption. ${ }^{15}$ It might be argued that the potential effect of GG on glucose absorption and on the insulinemic response may be less pronounced when a low-energy diet is consumed. However, it was even more interesting to assess whether such a mechanism would be effective with a low-energy diet. In this respect, in a separate study we found that addition of the same modified GG to a low-energy semisolid meal resulted in a more moderate change in blood glucose and insulin after meal ingestion. ${ }^{41}$ This may result in a prolonged feeling of satiety. ${ }^{16}$

Evidence for long-term weight maintenance with dietary fiber has been presented by a study by Hamilton and Anderson. ${ }^{42}$ In some studies lasting less than a year, GG supplementation was shown to be beneficial with respect to BW. ${ }^{17,18}$ However, in studies lasting more than a year, only Uusitupa et $a l^{43}$ found a slight reduction in BW after GG supplementation, while other studies did not find a beneficial effect of GG supplementation on weight control. ${ }^{44,45}$ The EI reduction observed in different short-term studies may be an acute effect and may disappear when fiber is supplemented for a longer period. This may be due to habituation to the fiber. ${ }^{44,46}$ Several studies examined the effect of fiber supplementation next to an energy-restricted diet on weight loss. Additional fiber intake next to a lowenergy diet has been shown to be effective in several studies $^{20,21}$ even during long-term treatment, ${ }^{23}$ but not in all. ${ }^{22}$ The prevention of increased hunger ratings when fiber is supplemented may improve compliance to an energyrestricted diet $^{6,20,23}$ and subsequently increase the chances of successful weight loss or prevention of weight gain.

In the present study, no significant difference in BW loss and EI was found between treatments. However, irrespective of the type of diet, the first treatment was more effective on $\mathrm{BW}$ loss compared to the second and third treatments. This could be associated with the fact that, at the beginning of the experiment, the subjects were more motivated. A second possible reason would be that subjects had already lost some weight during the first intervention and therefore further weight loss during the following treatments was more difficult to achieve. The SM-SSM+-SSM sequence, that is the sequence that started with the solid meal, was more effective on BW loss compared to the SSM + -SSM-SM sequence, that is the sequence that encled with the solid meal. Compliance to the treatment with the solid meal was less good compared to compliance with the treatments with the semisolid meals. Subjects had much more difficulty in following the treatment with the solid meal as it was prescribed compared to the semisolid meal treatments. Furthermore, at the end of the experiment, the subjects indicated that the ready-to-eat semisolid meal was much more easy to use compared with the solid meals that they had to prepare themselves. Therefore, a low energy self-prepared solid meal will probably only be effective when used at the beginning of 
a treatment. Thus, for longer-term treatments with a lowenergy meal, an alternating use of a ready-to-eat semisolid meal with a self-prepared solid meal might be more effective. Daily mean recorded EI as well as fat, carbohydrate and alcohol intake were not different between treatments, but they were reduced compared to baseline. Dietary fiber intake was reduced below the recommended level of $10 \mathrm{~g} / 1000 \mathrm{kcal}$ when the semisolid meal was used alone. This was not the case for the semisolid meal with GG and the solid meal. During dinner, when the subjects were allowed to eat what they liked, EI was similar for all four situations. This indicates that the low-energy diets were sufficient, because the subjects did not compensate for the lower EI during the day by eating more during dinner. The number of meals increased, which was a treatment condition, but the number of snacks decreased during intervention. Using solid meals, the subjects consumed fewer meals than using semisolid meals. This indicated a poorer compliance to the prescribed regimen. However, eating more snacks compensated for the reduced meal frequency.

A higher degree of underrecording was expected at baseline because, compared to the treatments when the subjects consumed three prescribed meals and only one meal was free, the subjects were free to eat whatever they liked. Because underrecording of food intake was similar in all situations, it was possible to use the data from the food intake diary in order to compare energy and macronutrient intake between treatments. Results from food intake diaries have been shown to be unreliable because of underrecording, especially in overweight/obese subjects. Underrecording in the present study $(18-24 \%)$ was higher compared to the results of Goris et $\mathrm{al}^{47}$ who found a $12 \%$ underrecording in obese men (BMI, $34.1 \mathrm{~kg} \mathrm{~m}^{-2}$ ) and no underrecording in highly motivated female dieticians with normal weight (BMI, $\left.22.1 \mathrm{~kg} \mathrm{~m}^{-2}\right)$. ${ }^{30}$ Scores on cognitive restrained eating increased during the intervention periods, indicating that dieting had an effect on this aspect of eating behavior. ${ }^{48}$ Because the subjects became more restrained, they were able to complete the treatment. However, the subjects were still classified as unrestrained (score $<9$ )

With respect to the effect of GG addition to a low-energy semisolid meal we conclude that the semisolid meal with or without GG and the solid meal were well tolerated and were effective on BW loss without affecting satiety negatively. However, in the case of the semisolid meal without GG and the solid meal, appetite-related parameters were increased, which was not the case for the semisolid meal with GG treatment, when these parameters remained at baseline level. Still, there was no significant difference between the appetite parameters of SSM + and SSM or SM. The semisolid meal with GG was found to be relatively more advantageous because it allowed a reduced EI together with the usual level of appetite scores and this treatment showed the higher preference, which observations contribute to possible compliance to such a diet on the longer term.
This type of treatment with three intervention periods of 2 weeks and washout periods in between has been shown to be relatively effective with respect to EI reduction and BW loss. During the treatments, EI was $3.3-3.5 \mathrm{MJ}$ lower compared to baseline, that is $142.8 \mathrm{MJ}$ over $3 \times 14$ days. For the whole group, EI reduction during treatments resulted in a BW loss of $4.4 \mathrm{~kg}$ for the entire intervention period. This BW loss was mainly attributed to a loss in body fat. Allison et al ${ }^{49}$ observed that decreased mortality rate is likely to be dependent on the degree to which weight is lost as fat and not on the degree of weight loss per se. Assuming that an EI deficit of $30 \mathrm{MJ}$ results in a BW loss of $1 \mathrm{~kg}^{50}$ an energy deficit of $132 \mathrm{MJ}$ is needed to lose $4.4 \mathrm{~kg}$. In other words, the observed energy deficit over $3 \times 14$ days ( $142.8 \mathrm{MJ}$ ) was in line with the expected energy intake reduction $(132 \mathrm{MJ})$ and related to $\mathrm{BW}$ loss. Given the relatively short periods of effort during treatments and the washout periods, in which the subjects were not undergoing any restriction, this indicates that an intermittent treatment might be successful, although the success changes from an emphasis on body weight loss into prevention of body weight gain.

With respect to the type of treatment we conclude that the intermittent treatment used may be advantageous for a weight reduction or weight maintenance program. The main reason for this is prevention of habituation by means of the washout periods ${ }^{44}$ and a more likely compliance because of the shorter periods of time.

\section{Acknowledgements}

This work was supported by Novartis Consumer Health Ltd, Nyon, Switzerland.

\section{References}

1 Seidell JC. Obesity in Europe. Obes Res 1995; 3(Suppl 2): 249s259 s.

2 Noppa $H$. Body weight change in relation to incidence of ischemic heart disease and change in risk factors for ischemic heart disease. Am J Epidemiol 1980; 111: 693-704

3 Hubert HB, Feinleib M, McNamara PM, Castelli WP. Obesity as an independent risk factor for cardiovascular disease: a 26-year follow-up of participants in the Framingham Heart Study. Circllation 1983; 67: 968-977.

4 Kromhout D. Body weight, diet, and serum cholesterol in 871 middle-aged men during $10 \mathrm{y}$ of follow-up (the Zutphen Study). Am I Clin Nutr 1983; 38: 591-598.

5 Doucet E, Imbeault P, St-Pierre S, Alméras N, Mauriège P, Richard $\mathrm{D}$, Tremblay A. Appetite after weight loss by energy restriction and a low-fat diet-exercise follow-up. Int J Obes Relat Metab Disord 2000; 24: $906-914$

6 Astrup A, Vrist E, Quaade F. Dietary fiber added to very low calorie diet reduces hunger and alleviates constipation. Int J Obes 1990; 14: $105-112$.

7 Stevens J. Does dietary fiber affect food intake and body weight? J Am Diet Assoc 1988; 88: 939 -942, 945.

8 Blundell JE, Burley VJ. Satiation, satiety and the actiuon of fibre on food intake. Int / Obes 1987; 11(Suppl 1): S9-S25.

9 Burley VJ, Blundell JE. Action of dietary fiber on the satiety cascade. In: Kritchevsky D, Bonfield C, Anderson JW (eds). Dietary fiber: chemistry, physiology, and health effects Plenum Press: New York, 1990. pp 227-246. 
10 Evans E, Miller DS. Bulking agents in the treatment of obesity. Nutr Metab 1975; 18: 199-203.

11. Pasman WJ, Wauters $M$, Westerterp-Plantenga MS, Saris WHM. Effect of one week of tibre supplementation on hunger and satiety or energy intake. Appetite 1997; 29: 77 - 87 .

12 Harju E. Increases in meal viscosity caused by addition of guar gum decrease postprandial activity and rate of emptying of gastric contents in healthy subjects. Panminerva Med 1985; 27: $125-128$.

13 Wilmshurst $P$, Crawley JCW. The measurement of gastric transit time in obese subjects using ${ }^{24} \mathrm{Na}$ and the effects of energy content and guar gum on gastric emptying and satiety. Br I Nutr $1980 ; 44: 1-6$

14 Blackburn NA, Holgate AM, Read NW. Does guar gum improve post-prandial hyperglycemia in humans by reducing small intestinal contact area? Br J Nutr 1984; 52; 197-204.

15 Blackburn NA, Redfern JS, Jariis H, Holgate AM, Hanning I, Scarpello JHB, Johnson IT, Read NW. The mechanism of action of guar gum in improving glucose tolerance in man. Clin Sci 1984; 66: $329-336$.

16 Leeds AR. Dietary fiber: mechanism of action. Int / Obes 1987 11(Suppl 1): S3-S7.

17 Tuomilehto J, Voutilainen E, Huttunen J, Vinni S, Homan K. Effect of guar gum on body weight and serum lipids in hypercholesterolemic females. Acta Med Scand 1980; 208: $45-48$.

18 Krotkiewski $M$. Effect of guar gum on body weight, hunger ratings and metabolism in obese subjects. $\mathrm{Br} /$ Nutr 1984; 52 : 97- 105 .

19 Hylander B, Rössner S. Effects of dietary fiber intake before meals on weight loss and hunger in a weight-reducing club. Acta Med Scand 1983; 213: 217-220

20 Solum TT, Ryttig KR, Solum E, Larsen S. The influence of highfibre diet on body weight, serum lipids and blood pressure in slightly overweight persons. A randomized, double-blind, plam cebo-controlled investigation with diet and fibre tablets (Dumovital). Int J Obes 1987; 11(Suppl 1): S67-S71.

21 Rössner S, Zweigbergk D von, Öhlin A, Ryttig K. Weight reduction with dietary fibre supplements. Results of two double-blind randomized studies. Acta Med Scand 1987; 222: 83-88.

22 Rössner, Andersson I-L, Ryttig K. Effects of a dietary fibre supplement to a weight reduction programme on blood pressure. A randomized, double-blind, placebo-controlled study. Acta Med Scand 1988; 223: 353-357.

23 Ryttig KR, Tellnes G Hægh L, Bøe E, Fagerthun H. A dietary fibre supplement and weight maintenance after weight reduction a randomized, double-blind, placebo-controlled long-term trial Int I Obes 1989; 13: $165-171$.

24 Schoeller DA, Santen E v, Peterson DW, Diez W, Jaspan J, Klein PD. Total body water measurement in humans with ${ }^{18} \mathrm{O}$ and ${ }^{2} \mathrm{H}$ labeled water. Am I Clin Nutr 1980; 33: 2686-2693.

25 Marken Lichtenbelt WD van, Westerterp KR, Wouters L. Detterium dilution as a method for determining total body water: effect of test protocol and sampling time. Br J Nitr 1994; 72: $491-497$.

26 Stunkard AJ, Messick S. The three-factor eating questionnaire to measure dictary restraint, disinhibition, and hunger. I Psychosom Res 1985; 29: $71-83$

27 Westerterp-Plantenga MS, Rolland V, Wilson SAJ, Westerterp, KR. Satiety related to $24 \mathrm{~h}$ diet-induced thermogenesis during high protein/carbohydrate $v s$ high fat diets measured in a respiration chamber. Eur J Clin Nutr 1999; 53: 1-8.

28 Herman CP, Polivy J. Restrained eating. In: Stunkard AJ (ed) Obesity. W.B. Saunders: Philadelphia; 1980. pp 208-225.

29 Stichting Nederlands Voedingsstoffenbestand. Nevo Tabel. Den Haag, Voorlichtingsbureau voor de voeding, 1996.

30 Goris AHC, Westerterp KR. Underreporting of habitual food intake is explained by undercating in highly motivated lean wormen. I Nutr 1999; 129: 878-882.

31 Fjeld CR, Brown $\mathrm{KH}$, Schoeller DA, Validation of the deuterium oxide method for measuring average daily milk intake. Am I Clin Nutr 1988; 48: $671-679$
32 Westerterp KR, Kayser B, Brouns F, Herry JP, Saris WHM. Energy expenditure climbing $\mathrm{M} \notin$ Everest. I Appl Physiol 1992; 73: 18151819.

33 Goris AHC, Westerterp KR. Improved reporting of habitual food intake after confrontation with earlier results on food reporting. Br J Nutr 2000; 83: 363-369.

34 Goldstein DJ. Beneficial effects of modest weight loss. Int J Obes Relat Metab Disord 1992; 16: 397-415.

3.5 Gaal LF van, Wauters MA, Leeww IH de. The beneficial effets of modest weight loss on cardiovascular risk factors. Int J Obes Relat Metab Disord 1997; 21(Suppl 1): S5-S9.

36 Porikos $\mathrm{K}$, Hagamen $\mathrm{S}$. Is fiber satiating? Effects of a high fiber preload on subsequent food intake of normal-weight and obese young men. Appetite 1986; 7: 153-162.

37 Rydning A, Berstad A, Berstad T, Hertzenberg L. The effect of guar gum and fiber-enriched wheat bran on gastric emptying of a semisolid meal in healthy subjects. Scand / Gastroenterol 1985; 20: $330-334$.

38 Lavin JH, Read NW. The effect on hunger and satiety of slowing the absorption of glucose: relationship with gastric emptying and postprandial blood glucose and insulin responses. Appetite 1995; 25: $89-96$.

39 Meier R, Beglinger C, Schneider H, Rowedder A, Gyr K. Effect of a liquid diet with and without soluble fiber supplementation on intestinal transit and cholecystokinin release in volunteers. I Parenteral Enteral Nutr 1993; 17: 231 - 235

40 Nieuwenhoven MA van, Kovacs EMR, Martin A-M, Brummer RJM, Westerterp-Plantenga MS, Brouns F. The effect of different dosages of guar gum on the rate of gastric emptying and intestinal transit of a consumed semisolid meal. I Am Coll Nutr 2000, (in press).

41 Kovacs EMR, Westerterp-Plantenga MS, Saris WHM, Melanson KJ, Goossens I, Geurten P, Brouns F. The effect of guar gum addition to a semisolid meal on appetite and blood parameters. Am $\mathrm{C} \mathrm{Clin}$ Nutr 2000 (submitted).

42 Hamilton CC, Anderson JW. Fiber and weight maintenance. I Fla Med Assoc 1992; 79:379-381.

43 Uusitupa $M$, Siitonen O, Savolainen K, Silvasti $M$, Penttilä I, Parviainen M. Metabolic and nutritional effects of long-term use of guar gum in the treatment of non-insulin dependent diabetes of poor metabolic control. J Clin Nutr 1989; 49: $345-$ 351 .

44 Pasman WJ, Westerterp-l'lantenga MS, Muls E, Vansant G, Ree J van, Saris WHM. The effectiveness of long-term fiber supplementation on weight maintenance in weight-reduced women. Int I Obes Relat Metab Disord 1997; 21: 548-555.

45 Simons LA, Gayst S, Balasubramaniam S, Ruys J. Long-term treatment of hypercholesterolaemia with a new palatable formulation of guar gum. Atherosclerosis $1982 ; 45: 101-108$.

46 Florent C, Flourie B, Leblond A, Rautureau M, Bernier J-J, Rambaud J-C. Influence of chronic lactulose ingestion on the colonic metabolism of lactulose in man (and in vivo study). I Clin Invest $1985 ; 75: 608-613$.

47 Goris AHC, Westerterp-Plantenga MS, Westerterp KR. Undereating and underrecording of habitual food intake in obese men: selective underreporting of fat intake. Am J Clin Nutr 2000; 71: $130-134$

48 Westerterp-Plantenga MS, Kempen KPG, Saris WHM. Determinants of weight maintenance in women after diet-induced weight reduction. Int J Obes Relat Metab Disord 1998; 22: 1-6.

49 Allison DB, Zannolli R, Faith MS, Heo M, Pietrobelli A, Van Itallie TB, Pi-Sunyer FX, Heymsfield SB. Weight loss increases and fat loss decreases all-cause mortality rate: results from two independent cohort studies. Int I Obes Relat Metab Disord 1999; 23 : $603-611$.

50 Westerterp, KR, Donkers JHHLM, Fredrix EWHM, Boekhoudt P. Energy intake, physical activity and body weight: a simulation model. / Nutr 1995; 73: 337-347. 